Published by Avanti Publishers

International Journal of Architectural

Engineering Technology

ISSN (online): 2409-9821

\title{
Imperfection Tolerances During the Erection of Steel Plate Girders and Geometrical Nonlinearities
}

\author{
Maël Sonna Donko ${ }^{1,3}$, Guillaume Hervé Poh'sié2 and Emanuele Maiorana4,* \\ ${ }^{1}$ Department of Civil Engineering, National Advanced School of Public Works of Yaounde, Cameroon. \\ ${ }^{2}$ College of Technology, University of Buea, Buea, Cameroon. \\ ${ }^{3}$ Department of Civil, Environmental and Architectural Engineering, University of Padua, Italy. \\ ${ }^{4}$ Collegio dei Tecnici dell'Acciaio, Milano, Italy.
}

\section{ARTICLE INFO}

Article Type: Research Article

Keywords:

Erection

GMNIA

Plate girder

Local instability

Initial imperfection

Timeline:

Received: August 31, 2021

Accepted: September 21, 2021

Published: October 08, 2021

Citation: Donko MS, Poh'sié GH, Maiorana E. Imperfection Tolerances During the Erection of Steel Plate Girders and Geometrical Nonlinearities. Int J Archit Eng Technol. 2021; 8: 22-36.

DOI: https://doi.org/10.15377/2409-9821.2021.08.3

\begin{abstract}
This work aims to prove that the strict initial imperfection tolerance limits proposed by the American AWS D1.1/D1.1M and the European EN 1090-2 codes could be relaxed for the webs of the most encountered steel I-plate girders subjected to local bendbuckling during their erection phase. To achieve this scope, a parametric study was done involving 36 perfect and 612 imperfect web models with varying aspect ratio, slenderness ratio, initial imperfection amplitude, and stress ratio using Abaqus/CAE by Finite Element (FE) linear buckling analyses then FE geometrically and materially nonlinear analyses with imperfections included (GMNIA). After investigating the results, two main research novelties were found. An easily applicable equation to determine the ultimate strength of webs subjected to direct stresses, which is a function of not only the slenderness ratio and stress ratio (as in other research) but also a function of the initial imperfection amplitude, was derived. Secondly, a tolerance limit equation that is a function of not only the slenderness ratio but also the stress ratio, thus considering the symmetry of the section of plate girders, has been derived. The derived tolerance limit equation provides acceptable and inclusive parameterwise imperfection tolerances for webs of plate girders so as to relax strict and costly tolerance limits. The results obtained show that for monosymmetric I-plate girders during erection, EN 1090-2 and AWS D1.1/D1.1M tolerance limits can be relaxed to around $40 \%$ and $80 \%$ in less slender webs and close to $60 \%$ and $200 \%$ in more slender webs, respectively.
\end{abstract}

\footnotetext{
*Corresponding Author Email: emaior@libero.it Tel: +39.347.9663945
}

(C2021 Donko et al. Published by Avanti Publishers. This is an open access article licensed under the terms of the Creative Commons Attribution Non-Commercial License which permits unrestricted, non-commercial use, distribution and reproduction in any medium, provided the work is properly cited. (http://creativecommons.org/licenses/by-nc/4.0/) 


\section{Introduction}

\subsection{Background}

Steel plates are widely used in many engineering fields to construct crane girders, ships, aerospace, offshore, gas, and liquid containment structures [1]. In bridge engineering, steel plates are common for slender plate girders capable of carrying higher loads over long spans. During a bridge's incremental launching process, the girder is pulled from one bridge pier to another, generating large bending moments due to the self-weight of the girder and the launching equipment [2]. If special attention is not given, instability of the slender web may occur after exhausting its post-buckling reserve strength. Plate girders subjected to the random nature of out-of-plane geometric imperfections [3] possess a reduced post-buckling strength, rendering them more unstable. In the 1970s, several girder bridges collapsed due to considerably high initial imperfections. Thus, rules like Merrison's rules were drafted to provide imperfection tolerances but were found to be in many cases strict for the fabricators and resulted in the too-high total cost of the structure. The IABSE (International Association for Bridges and Structural Engineering) Task group on Tolerances in Steel Plated Structures [4] was then created to set realistic and easily controlled tolerances. From then, a large amount of research was carried out to find a correlation between imperfections and post-buckling (ultimate) strength, thus finding imperfection tolerance limits that correspond to an acceptable drop in strength. Rangelov [5] and Sadovský [6] proposed strength-based formulations of fabrication tolerances that were used in codes. During the last 2 decades, with a boom in finite element (FE) approaches, Maiorana [7] concluded that imperfection amplitudes below the code's tolerance have minimum influence on the ultimate strength of webs subjected to patch loading. Through experimental and FE tests, Kala [8] demonstrated that it is not indispensable to abide by the stringent web tolerances and that imperfect webs of plate girders can be used without being straightened. Finally, while studying shear on web plates, Ghadami [1] derived an ultimate shear strength reduction factor as a function of initial imperfection and thus suggested a maximum permissible construction tolerance. The study of tolerances in the web of plate girders has to pass through in-depth knowledge of its ultimate strength. The following part explains this concept.

\subsection{Literature Review}

Theodore von Kármán's work on effective width (Figure 1) was a milestone concerning plates' simplified design methods. His hypothesis, to find the ultimate strength of a perfect plate, was that the fictitious plate of width $b_{\text {eff }}$ would have the critical stress equal to the yield stress as given by equation (1.1).

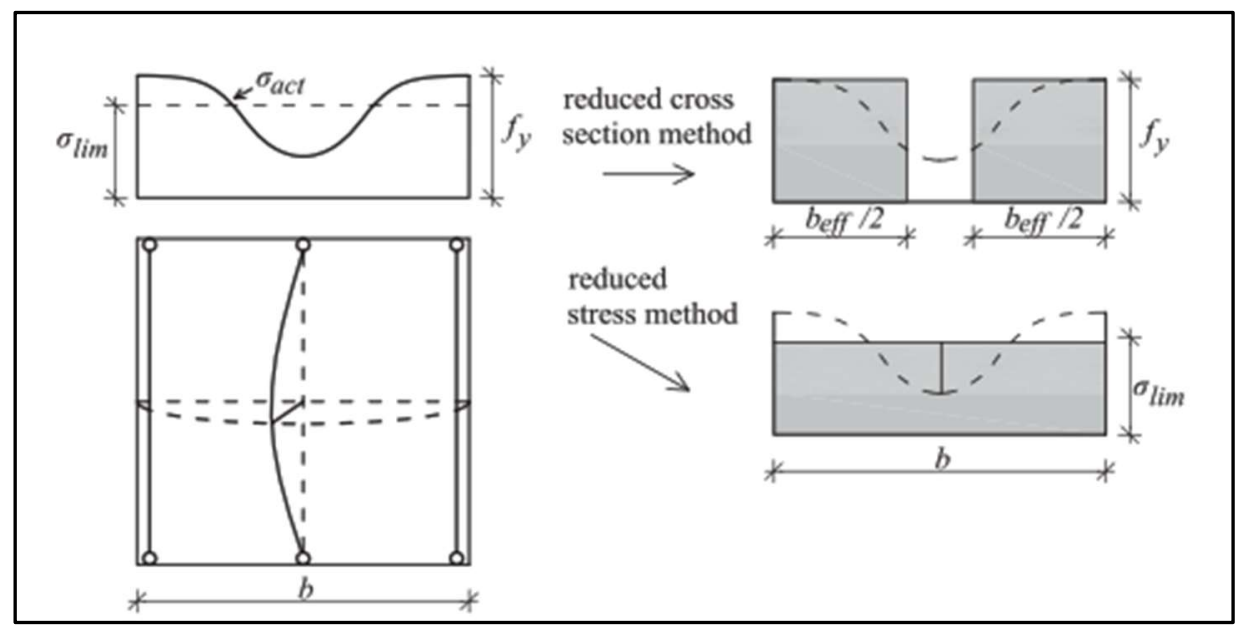

Figure1: Basic ideas of reduced cross-section method and reduced stress method [9].

$$
\sigma_{\mathrm{cr}}=\mathrm{f}_{\mathrm{y}}
$$

This was such that the effective width, $\mathrm{b}_{\text {eff }}$, and width reduction factor, $\rho$, could be written as in equations (1.2) 
and (1.3), respectively. Where, $\bar{\lambda}_{\mathrm{p}}$ is the von Kármán's slenderness ratio.

$$
\begin{aligned}
& b_{\text {eff }}=b \sqrt{\frac{f_{y}}{\sigma_{c r}}} \\
& \rho=\frac{b_{\text {eff }}}{b}=\frac{1}{\bar{\lambda}_{p}}
\end{aligned}
$$

Many researchers followed his work to derive an expression from describing a real plate with inherent initial imperfections. One of the most known and widely spread design codes is the one proposed by Winter in 1947. Winter conducted numerous experimental tests on cold-formed specimens and proposed a refined expression for the effective width given by equation (1.4).

$$
\rho=\left\{\begin{array}{c}
1, \quad \bar{\lambda}_{p} \leq 0.673 \\
\frac{1}{\overline{\bar{\lambda}}_{\mathrm{p}}}\left(1-\frac{0.22}{\bar{\lambda}_{\mathrm{p}}}\right), \quad \bar{\lambda}_{\mathrm{p}}>0.673
\end{array}\right.
$$

Although huge efforts have been put into this research field, the Winter function, based on cold-formed members, is used in the present design code of EN 1993-1-5 [10], but its use is highly contested for plate girders $[11,12]$. Also, modified width ratios were proposed to take into account loading conditions different from uniformly compressive loads. EN 1993-1-5 proposes equation (1.5).

$$
\begin{aligned}
& \rho=\left\{\begin{array}{c}
1, \quad \bar{\lambda}_{\mathrm{p}} \leq 0.5+\sqrt{0.085-0.055 \psi} \\
\frac{\bar{\lambda}_{\mathrm{p}}-0.055(3+\psi)}{\bar{\lambda}_{\mathrm{p}}{ }^{2}} \leq 1.0, \quad \bar{\lambda}_{\mathrm{p}}>0.5+\sqrt{0.085-0.055 \psi}
\end{array}\right. \\
& \text { where } \bar{\lambda}_{\mathrm{p}}=\sqrt{\frac{\mathrm{f}_{\mathrm{y}}}{\sigma_{\mathrm{cr}}}}
\end{aligned}
$$

The ultimate strength of the plate is obtained by calculating the stress (maximum compressive) in the initial cross-section for which the reduced (effective) cross-section is at the onset of yielding in the most compressed fiber $[9,13-16]$.

\subsection{Aims and Scopes}

The increased use of slender steel I-shaped plate girders in the world in general and developing countries in particular, coupled with the too strict web imperfection tolerance limits given by codes, has augmented the need for in-depth research on buckling and post-buckling of webs. An easily applicable equation to determine the ultimate strength of webs subjected to direct stresses, which is a function of initial imperfection amplitude, has not been found in the literature. Also, through an equation, the assessment of acceptable imperfection tolerances for webs of monosymmetric plate girders, in a manner to relax strict and costly tolerance limits, has not yet been reported in the literature.

Many different parameters may influence the ultimate strength of the web of steel plate girders. In the course of their study, researchers [1,6,7,17-19] have focused on aspect ratio, slenderness ratio, plate loading condition (stress ratio), or initial imperfection amplitude as they are the most influential parameters. Thus, this study aims to evaluate the ultimate strength formulation proposed by the European standard, determine the effects of the parameters mentioned above on its ultimate strength, investigate possible tolerance limit relaxation, which will be highly welcomed by fabricators-erectors, and identify trends then use regression analysis to derive both ultimate strength and a relaxed tolerance limit equation [20]. 


\section{Materials and Methods}

\subsection{Material Properties}

Von Mises' stresses experienced by slender webs of plate girders [21] are found to always be below or at its yield strength. As such, an elastic with perfectly plastic steel behavior with no strain hardening was used in the course of this study as it is capable of perfectly describing the pre- and post-buckling behavior of the webs until it reaches its ultimate strength. Thus, the most commonly found plate girder steel properties were used: $\mathrm{E}=$ $206000 \mathrm{MPa}, v=0.3$ and $\mathrm{f}_{\mathrm{y}}=355 \mathrm{MPa}$.

\subsection{Geometry, Loading, and Boundary Conditions}

To achieve this work's objectives, 36 perfect and 612 imperfect web models found by varying aspect ratio, slenderness ratio, stress ratio, and initial imperfection amplitude were modelled using FE software Abaqus/CAE [22]. Three webs with span lengths of $a=1500 \mathrm{~mm}, 2250 \mathrm{~mm}$, and $3000 \mathrm{~mm}$ and equal web depth of $\mathrm{b}=1500 \mathrm{~mm}$ are selected. A generic geometry is shown in Figure 2. Using these three webs, 12 models with various web thicknesses, $\mathrm{t}$, are generated and shown in Table $\mathbf{1}$.

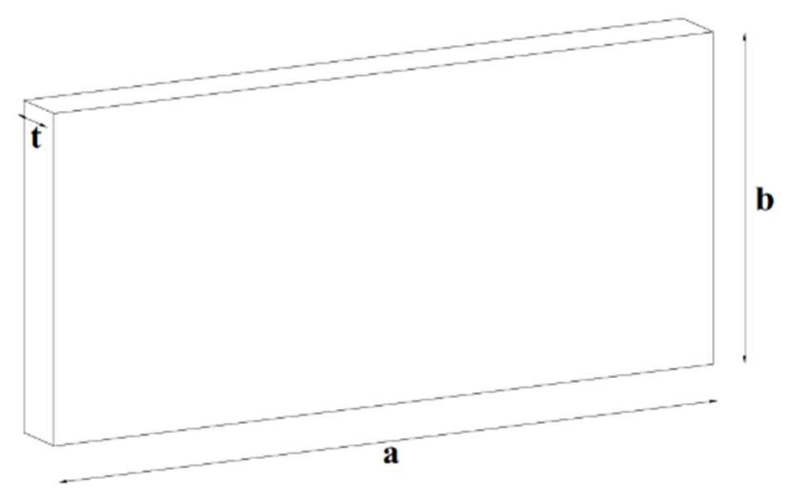

Figure 2: The geometry of the web of a plate girder.

Table 1: Dimensions of webs studied.

\begin{tabular}{|c|c|c|c|c|c|}
\hline ID & b $(\mathrm{mm})$ & $\mathrm{a}(\mathrm{mm})$ & $\mathrm{t}(\mathrm{mm})$ & $\boldsymbol{\alpha}=\frac{\mathbf{a}}{\mathbf{b}}$ & $\boldsymbol{\beta}=\frac{b}{t}$ \\
\hline P1a & \multirow{4}{*}{1500} & \multirow{4}{*}{1500} & 6 & \multirow{4}{*}{1} & 250 \\
\hline P1b & & & 8 & & 187.5 \\
\hline P1c & & & 10 & & 150 \\
\hline P1d & & & 12 & & 125 \\
\hline P2a & \multirow{4}{*}{1500} & \multirow{4}{*}{2250} & 6 & \multirow{4}{*}{1.5} & 250 \\
\hline $\mathbf{P} 2 \mathbf{b}$ & & & 8 & & 187.5 \\
\hline P2c & & & 10 & & 150 \\
\hline P2d & & & 12 & & 125 \\
\hline P3a & \multirow{4}{*}{1500} & \multirow{4}{*}{3000} & 6 & \multirow{4}{*}{2} & 250 \\
\hline P3b & & & 8 & & 187.5 \\
\hline P3c & & & 10 & & 150 \\
\hline P3d & & & 12 & & 125 \\
\hline
\end{tabular}


Loading conditions, through a change of flange symmetry and thus stress ratios, $\psi$, are varied from pure compression, eccentric compression to pure bending yielding 36 perfect web models. Pure compression is included as it represents the basic loading condition used in most theoretical studies of plates. These webs are chosen in such a way that column type buckling in the web is avoided $(\alpha \geq 1)$, web buckling is solicited $\left(\frac{\mathrm{b}}{\mathrm{t}} \geq \sqrt{\mathrm{k}_{\mathrm{cr}} \cdot \frac{\pi^{2}}{12\left(1-v^{2}\right)} \cdot \frac{\mathrm{E}}{\mathrm{f}_{\mathrm{y}}}}\right)$ and flange-induced buckling is avoided $(\beta \leq 250)$ [23-25]. A generic loading is shown in Figure 3.

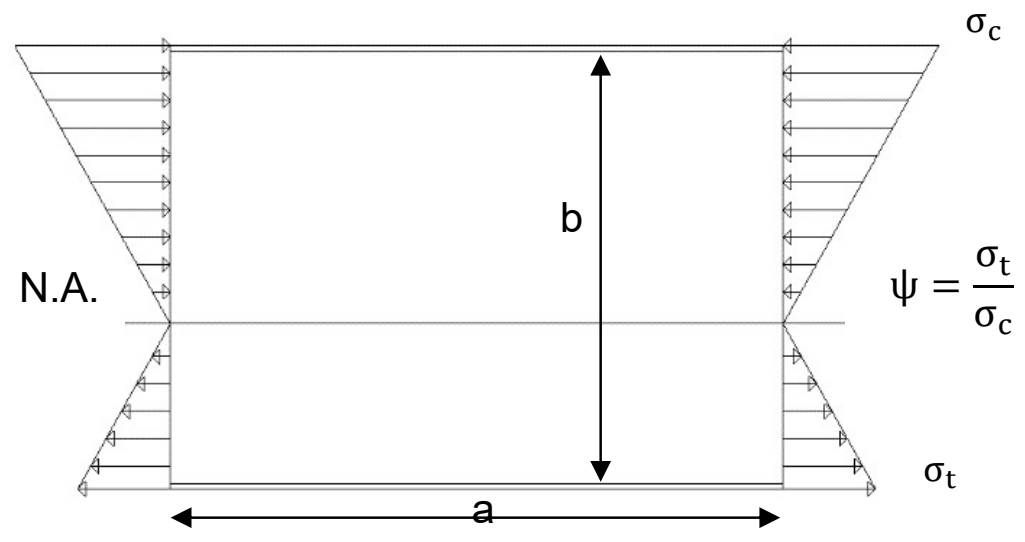

Figure 3: Generic web loading in web due to changing flange symmetry.

To investigate the effect of geometric imperfections on the ultimate strength and thus obtain a tolerance limit, 17 initial imperfection amplitudes shown in Table $\mathbf{2}$ are included in the models, making 612 imperfect web models. The lowest imperfection amplitude is chosen to stimulate the minimum bifurcation-type buckling, and the highest is taken so that the model does not fail before buckling.

Table 2: Initial imperfection amplitudes.

\begin{tabular}{|c|c|c|}
\hline Imperfection & Parameter, k & Amplitude, $\mathbf{b} / \mathbf{k}(\mathbf{m m})$ \\
\hline $\operatorname{Imp}_{1}$ & 100000 & 0.015 \\
\hline $\operatorname{Imp}_{2}$ & 10000 & 0.15 \\
\hline $\mathrm{Imp}_{3}$ & 1000 & 1.5 \\
\hline $\operatorname{Imp}_{4}$ & 500 & 3 \\
\hline $\operatorname{Imp}_{5}$ & 300 & 5 \\
\hline $\operatorname{Imp}_{6}$ & 200 & 7.5 \\
\hline $\operatorname{Imp}_{7}$ & 150 & 10 \\
\hline $\operatorname{Imp}_{8}$ & 125 & 12 \\
\hline $\operatorname{Imp}_{9}$ & 100 & 15 \\
\hline $\operatorname{Imp}_{10}$ & 80 & 18.75 \\
\hline $\operatorname{Imp}_{11}$ & 60 & 25 \\
\hline $\operatorname{Imp}_{12}$ & 50 & 30 \\
\hline $\operatorname{Imp}_{13}$ & 40 & 37.5 \\
\hline $\operatorname{Imp}_{14}$ & 30 & 50 \\
\hline $\operatorname{Imp}_{15}$ & 20 & 75 \\
\hline $\operatorname{Imp}_{16}$ & 15 & 100 \\
\hline $\operatorname{Imp}_{17}$ & 10 & 150 \\
\hline
\end{tabular}


Different boundary conditions inspired by reference [7] were studied under various loading conditions. The chosen one, shown in Figure 4, complies with the analytical formulations for buckling stress and the ultimate strength. As such, out-of-plane restraints were applied on the four sides, horizontal restraints applied in the two middle nodes of the horizontal sides, and vertical restraints applied on the vertical sides. The restraints dispositions described were chosen to simulate the flanges' and stiffeners' behaviors adequately.

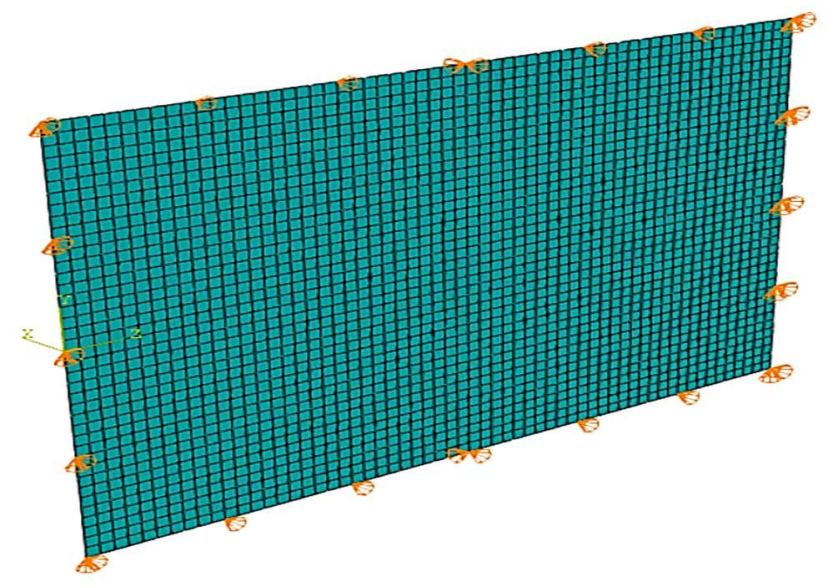

Figure 4: Web plate boundary conditions, mesh density of 40 .

\subsection{Numerical Modeling and Verification}

\subsubsection{Numerical Modeling}

For the study of the web of plate girders, the web was modeled as a deformable shell-type part with the elastic perfectly plastic steel properties stated above. With the given geometrical dimensions assigned, an S4R FE was used. This three-dimensional, doubly-curved, four-node shell element with six degrees of freedom per node uses bilinear interpolation with reduced integration. The S4R FE was used with a mesh density of 40, obtained after a mesh convergence study performed [26], and based on the difference between the critical stress obtained through Abaqus/CAE and the analytical results. The loads were applied at the vertical edges as normal tractiontype.

Firstly, a linear perturbation type buckle step was used to perform a linear buckling analysis, and thus, eigenvalues and eigenmodes were obtained. Also, GMNIA analyses were used to capture both the pre- and postbuckling responses of the imperfect webs under given loading conditions and, most importantly, to get the ultimate strength of the webs. As imperfections were included in this analysis [27], the perfect web was modified to include imperfections by calling the eigenmode obtained in the previous linear buckling analysis and setting the appropriate initial imperfection amplitude [28]. Abaqus/Standard dealt with this by finding, through a Static Riks step, the behavior under progressive loading of the web and thus its ultimate strength [29-34].

\subsubsection{Verification of Modeling Process}

Basler's experiment [35] on welded plate girders was simulated numerically (Figure 5) in view of obtaining results similar to the experimental ones and thus, confirmed the finite element modeling procedures used to study the web. Basler's Test T1 on Girder G4 is chosen as it experiences direct stresses, which are the stresses dealt with in the present study.

At ultimate load, the FE model was deformed, as shown in Figure 6. Experimental and FE load vs. vertical displacement curves were plotted on the same graph, shown in Figure 7, and compared. As explained in Basler's report [36], it should be noted that the curve representing the dynamic response of Girder G4 is not considered when digitising the graph [37]. 


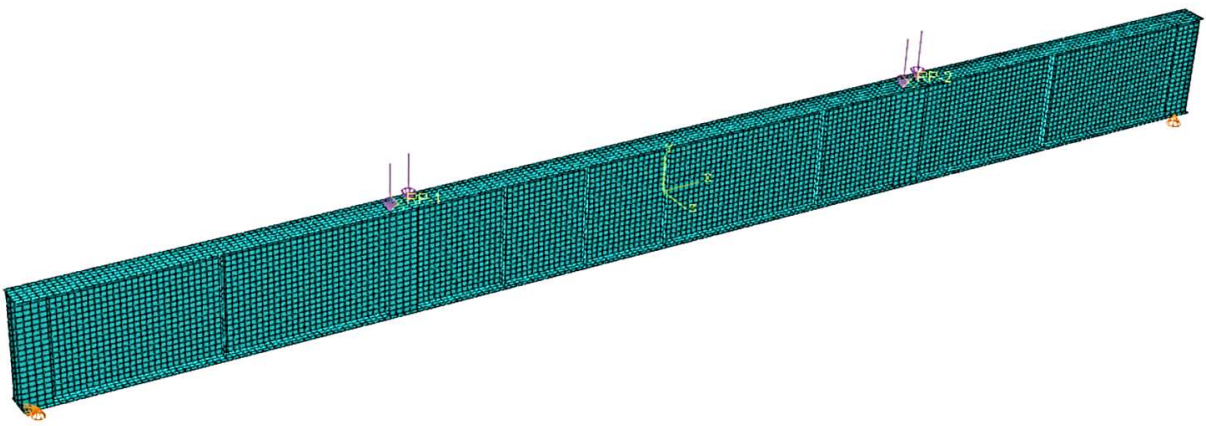

Figure 5: Numerical model of Girder G4, Test T1.

The FE results were found almost perfectly to coincide with the experimental results [36]. An overall maximum deviation of $7.70 \%$ is found at $\mathrm{v}=2.44 \mathrm{in}$. This overall maximum deviation occurs after the ultimate state. Thus, this part is not considered in this study as only realistic situations were dealt with here (situations before failure load). Thus, in the realistic range, a maximum deviation of $3.18 \%$ occurs at $\mathrm{v}=1.60 \mathrm{in}$.

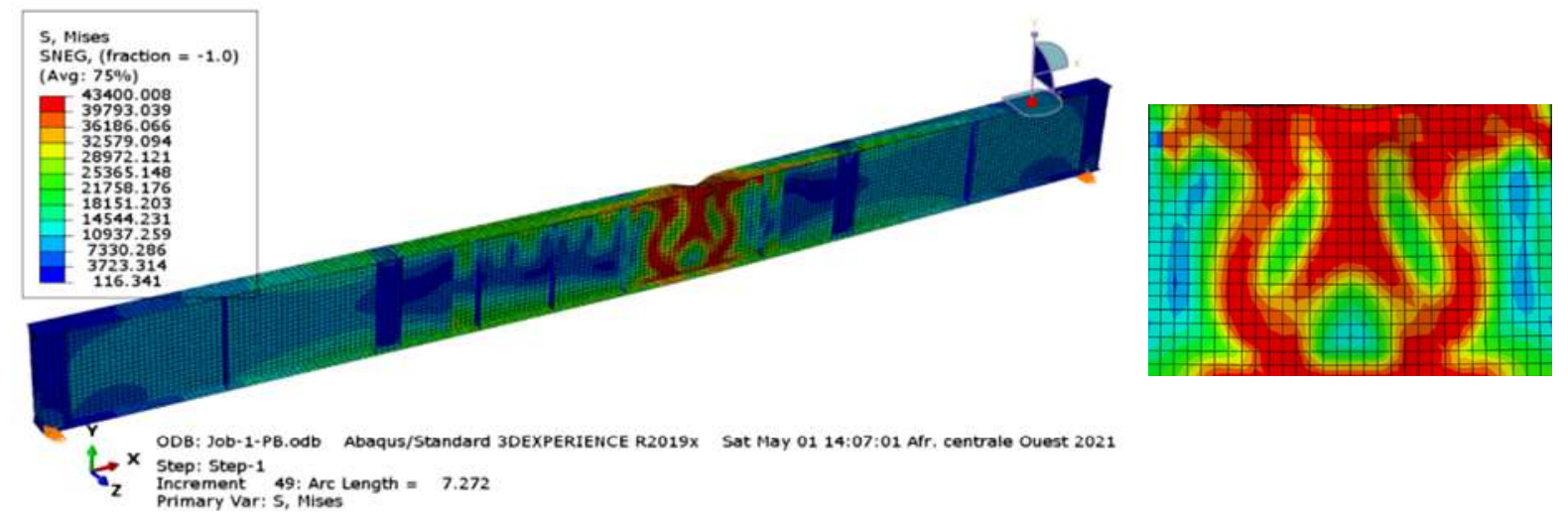

Figure 6: Global and Local State of the web at ultimate load, units: psi, 1 psi $=6.89 \mathrm{kPa}$.

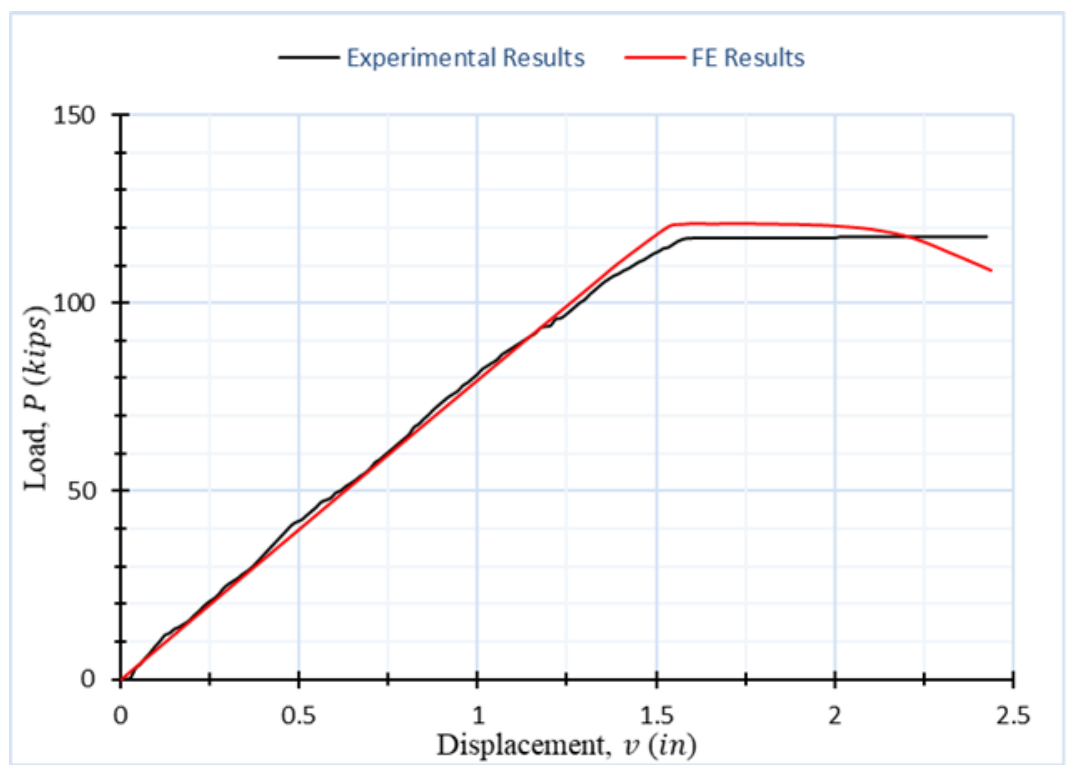

NB: 1 in $=25.4 \mathrm{~mm}$ and 1 kip $=4.45 \mathrm{kN}$

Figure 7: Experimental and FE graphical comparison. 
The FE results obtained were found to deviate from the experimental ones by not more than $10 \%$. More so, in this realistic range, deviations of less than $5 \%$ were dealt with. Therefore, the FE modeling process was considered valid for subsequent GMNIA analyses.

\section{Results and Discussion}

\subsection{Comparison between EC3-1-5 and FE Ultimate Strength}

Here, the ultimate strength computed from EC3-1-5 and the FE results considering an imperfection amplitude of $\operatorname{Imp}_{1}=0.015 \mathrm{~mm}$, and the corresponding eigenmode (Table 3) were summarised and compared in Table 4.

Table 3: Buckling shape or eigenmode of web plates.

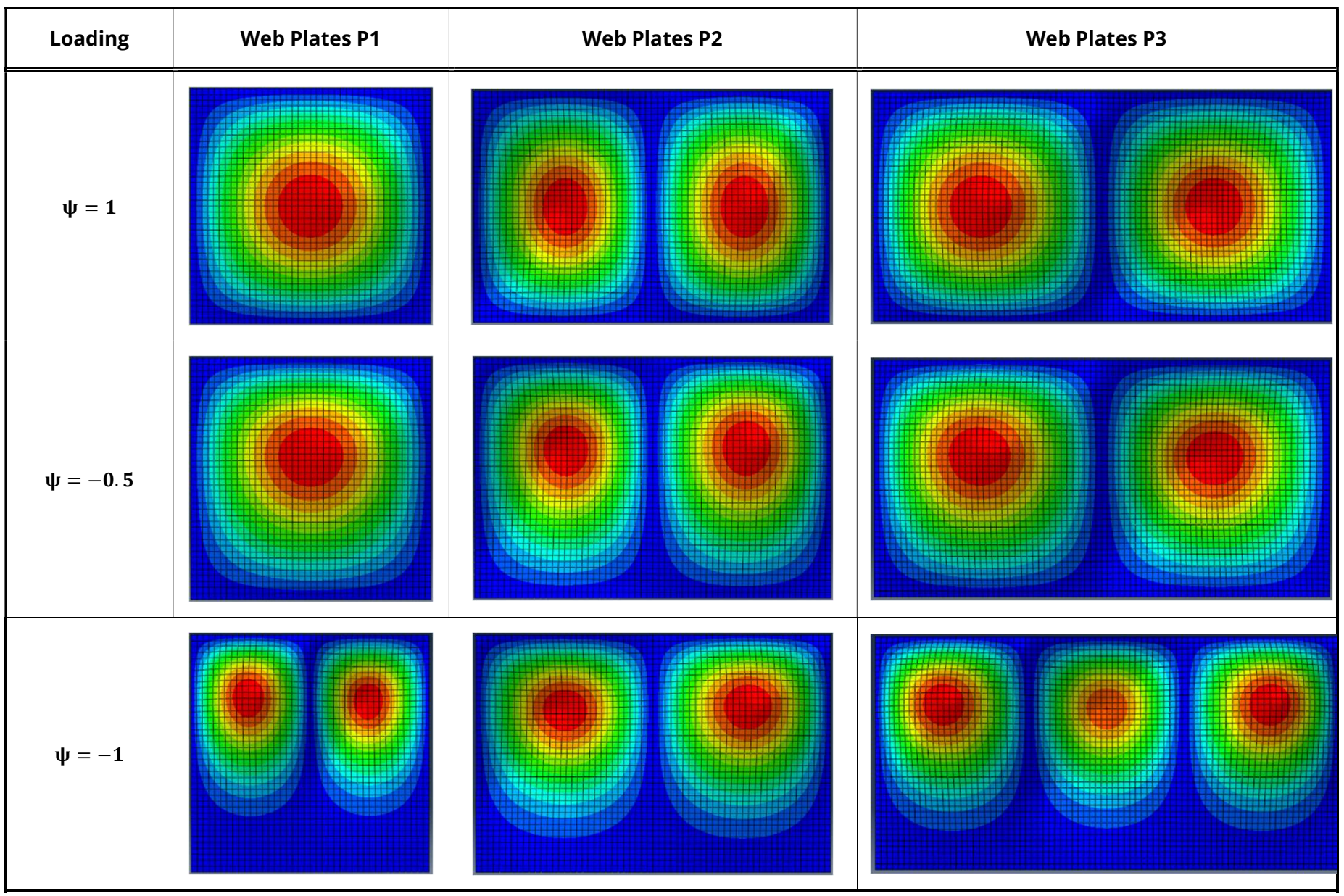

Results show that in slender plates, when $\psi=-0.5$ and -1 , the EC3-1-5 analytical ultimate strength deviates a lot from the FE results with a maximum deviation of up to $24.91 \%$. However, high deviations in slender plates are normal as many tests showed that Winter's function (used in EC3-1-5) tends to overestimate the ultimate resistance of slender plates because the Winter's equation was derived from his experiments on cold-formed plates different from the hot-rolled plates that make up steel plate girders [11, 12].

\subsection{Effects of Parameters on Ultimate Strength}

The effect of every parameter was studied, having obtained the ultimate strength values of 612 imperfect web models. The results obtained were presented on a logarithmic scale, which best suits its behavior. The effect of initial imperfection amplitude (amplitude parameter, k) is implicitly represented in every graph drawn using Graph Expert Professional [37]. 
Table 4: EC3-1-5 and FE ultimate strength comparison.

\begin{tabular}{|c|c|c|c|c|c|c|c|c|c|c|c|}
\hline \multirow[t]{2}{*}{ ID } & \multirow{2}{*}{$\alpha=\frac{\mathbf{a}}{\mathbf{b}}$} & \multirow{2}{*}{$\boldsymbol{\beta}=\frac{\mathbf{b}}{\mathbf{t}}$} & \multicolumn{3}{|c|}{$\begin{array}{l}\text { Pure Compression } \\
\qquad \Psi=1\end{array}$} & \multicolumn{3}{|c|}{$\begin{array}{l}\text { Eccentric } \\
\psi=-0.5\end{array}$} & \multicolumn{3}{|c|}{$\begin{array}{l}\text { Pure Bending } \\
\qquad \Psi=-1\end{array}$} \\
\hline & & & $\mathbf{f}_{\text {u.EC3 }}$ & $\mathbf{f}_{\mathrm{u} . \mathrm{FE}}$ & $\Delta \mathbf{f}_{\mathbf{u}} \%$ & $\mathbf{f}_{\mathrm{u} . \mathrm{EC} 3}$ & $\mathbf{f}_{\mathbf{u} . \mathrm{FE}}$ & $\Delta \mathbf{f}_{\mathbf{u}} \%$ & $\mathbf{f}_{\mathrm{u} . \mathrm{EC} 3}$ & $\mathbf{f}_{\mathbf{u} . \mathrm{FE}}$ & $\Delta \mathbf{f}_{\mathbf{u}} \%$ \\
\hline P1a & 1 & 250 & 62.42 & 57.26 & 9.01 & 159.17 & 127.42 & 24.91 & 180.76 & 173.39 & 4.25 \\
\hline P1b & 1 & 187.5 & 82.06 & 74.71 & 9.83 & 193.59 & 169.40 & 14.28 & 222.62 & 227.98 & 2.35 \\
\hline P1c & 1 & 150 & 101.12 & 92.41 & 9.42 & 224.03 & 211.96 & 5.69 & 261.43 & 278.07 & 5.98 \\
\hline P1d & 1 & 125 & 119.59 & 110.76 & 7.97 & 251.37 & 258.68 & 2.82 & 297.89 & 332.21 & 10.33 \\
\hline $\mathbf{P} 2 \mathrm{a}$ & 1.5 & 250 & 62.42 & 59.70 & 4.55 & 159.17 & 129.44 & 22.96 & 180.76 & 171.52 & 5.39 \\
\hline $\mathbf{P} 2 \mathbf{b}$ & 1.5 & 187.5 & 82.06 & 77.66 & 5.67 & 193.59 & 171.40 & 12.94 & 222.62 & 226.93 & 1.90 \\
\hline P2c & 1.5 & 150 & 101.12 & 95.60 & 5.77 & 224.03 & 213.61 & 4.88 & 261.43 & 287.66 & 9.12 \\
\hline P2d & 1.5 & 125 & 119.59 & 113.12 & 5.73 & 251.37 & 253.43 & 0.81 & 297.89 & 340.56 & 12.53 \\
\hline P3a & 2 & 250 & 62.42 & 58.81 & 6.14 & 159.17 & 128.51 & 23.85 & 180.76 & 171.91 & 5.15 \\
\hline P3b & 2 & 187.5 & 82.06 & 76.18 & 7.71 & 193.59 & 170.89 & 13.29 & 222.62 & 225.59 & 1.32 \\
\hline P3c & 2 & 150 & 101.12 & 94.12 & 7.44 & 224.03 & 214.31 & 4.54 & 261.43 & 284.03 & 7.96 \\
\hline P3d & 2 & 125 & 119.59 & 112.68 & 6.13 & 251.37 & 257.97 & 2.56 & 297.89 & 335.78 & 11.29 \\
\hline
\end{tabular}

The 3D graph of Figure $\mathbf{8}$ shows that a change in aspect ratio does not significantly influence the ultimate strength of the web of plate girders as the curves are superimposed. This situation occurs no matter the imperfection amplitude. Figure 9 shows that an increase in the slenderness ratio leads to a decrease in the ultimate strength of the plate, no matter the imperfection amplitude. The rate at which the strength decreases is increased as the slenderness ratio decreases. Also, Figure 10 reveals that as loading changes from pure compression ( $\psi=1)$ to pure bending $(\psi=-1)$, the strength of the plate increases.

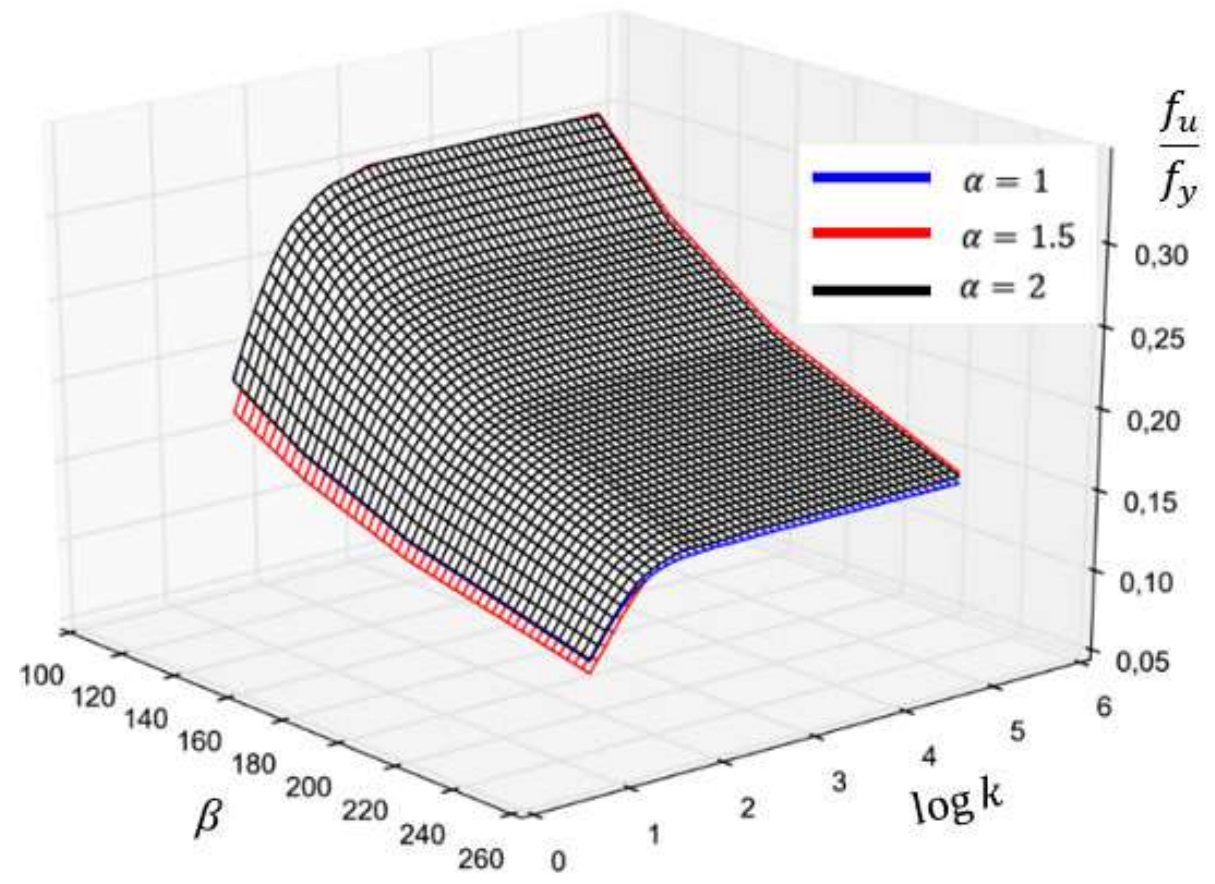

Figure 8: 3D graphical summary of the effect of aspect ratio. 


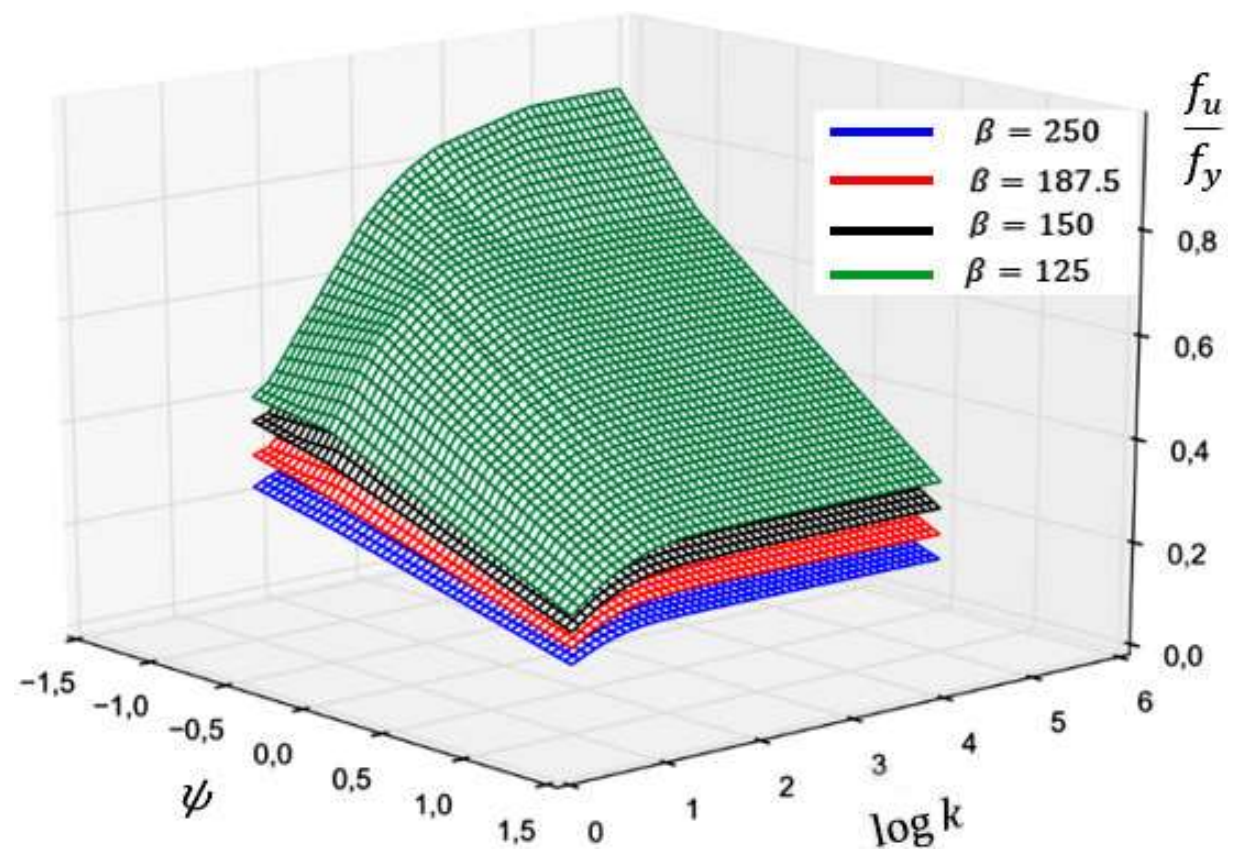

Figure 9: 3D graphical summary of the effect of slenderness ratio.

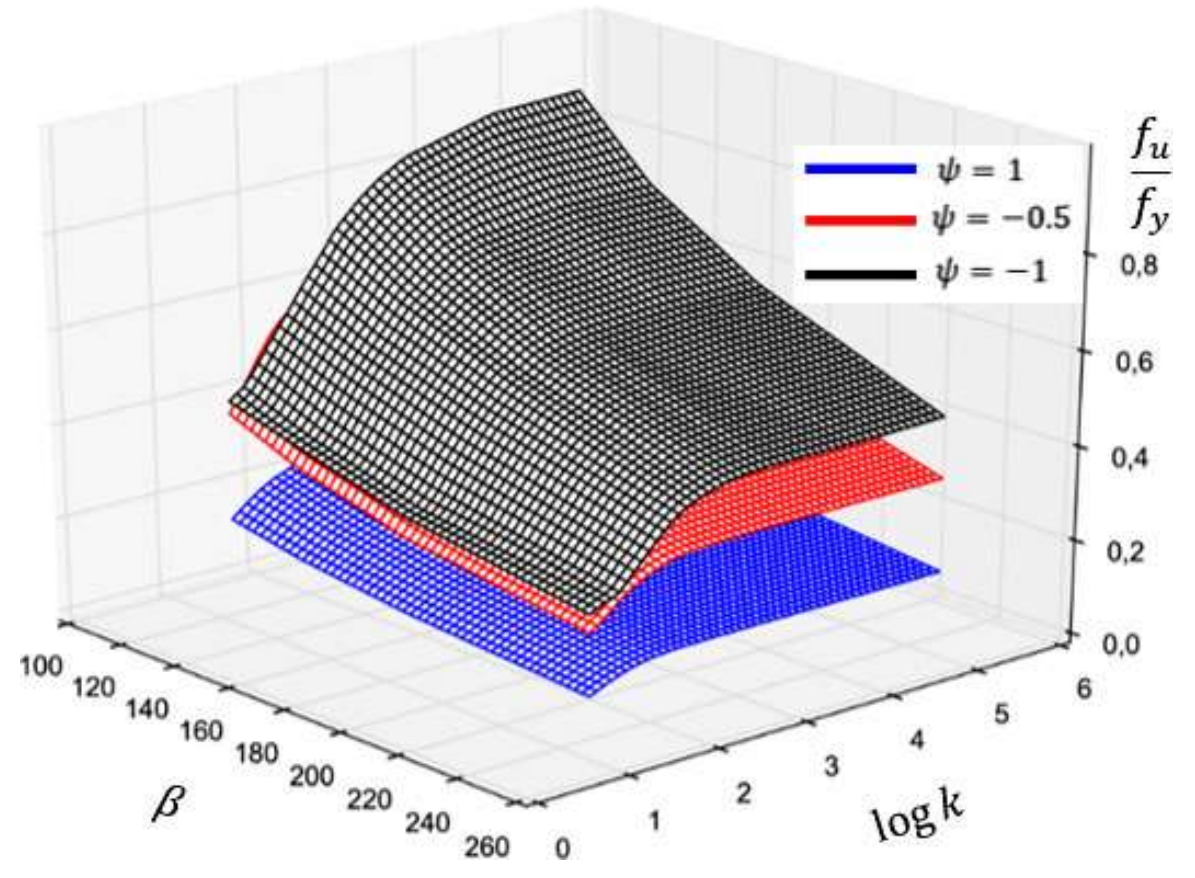

Figure 10: 3D graphical summary of the effect of stress ratio.

\subsection{Proposed Ultimate Strength Equation}

\subsubsection{Derivation}

Multiple nonlinear regression analysis techniques using Curve Expert Professional [38] were used to study the effect of loading condition (stress ratio), slenderness ratio, and initial imperfection amplitude on the strength. The equation obtained (3.1) have correlation coefficients of determination, $\mathrm{R}^{2}=99.32 \%$ and $\mathrm{R}=99.66 \%$. These results show excellent conformity between the derived equation and the FE nonlinear results. 


$$
\begin{gathered}
\forall \alpha \in[1,2], \forall \beta \in[125,250], \forall \delta \in\left[\frac{\mathrm{b}}{100000}, \frac{\mathrm{b}}{20}\right] \text { and } \forall \psi \in[-1,1] \\
\frac{\mathrm{f}_{\mathrm{u}}}{\mathrm{f}_{\mathrm{y}}}(\psi, \beta, \delta)=\frac{1.54-0.445 \cdot \psi-0.002 \cdot \beta+0.0024 \cdot \delta}{1+0.3 \cdot \psi+0.0108 \cdot \beta+0.024 \cdot \delta}
\end{gathered}
$$

\subsubsection{Verification}

A web model, different from the ones used in the analyses, was selected from the range of studies to verify the equation derived. This web had properties given in equation (3.2).

$$
\left\{\begin{array} { c } 
{ a = b = 1 2 0 0 \mathrm { mm } } \\
{ \mathrm { t } = 6 \mathrm { mm } }
\end{array} \Rightarrow \left\{\begin{array}{c}
\alpha=1 \\
\beta=200
\end{array}\right.\right.
$$

The chosen web of plate girder is subjected to an eccentric compression with stress ratio $\psi=0.5$. It is modeled using the verified FE modeling procedure. The FE results obtained and the results given by the derived formula are presented in Table $\mathbf{5}$ and compared.

The results obtained here show a maximum deviation of $9.69 \%$. Thus, this example confirms the reliability of

\begin{tabular}{|c|c|c|c|c|c|}
\hline Imperfection & $\mathbf{k}$ & $\boldsymbol{\delta}=\frac{\mathbf{b}}{\mathbf{k}}(\mathbf{m m})$ & $\frac{f_{u, F E}}{f_{y}}$ & $\frac{\mathbf{f}_{\mathrm{u}, \text { Equation }}}{\mathbf{f}_{\mathbf{y}}}$ & $\Delta \frac{\mathbf{f}_{\mathbf{u}}}{\mathbf{f}_{\mathbf{y}}}$ \\
\hline $\operatorname{Imp}_{1}$ & 100000 & 0.012 & 0.253 & 0.277 & 9.69 \\
\hline $\operatorname{Imp}_{2}$ & 10000 & 0.12 & 0.253 & 0.277 & 9.69 \\
\hline $\operatorname{Imp}_{3}$ & 1000 & 1.2 & 0.253 & 0.276 & 9.09 \\
\hline $\mathrm{Imp}_{4}$ & 500 & 2.4 & 0.252 & 0.274 & 8.78 \\
\hline $\operatorname{Imp}_{5}$ & 300 & 4 & 0.251 & 0.272 & 8.29 \\
\hline $\operatorname{Imp}_{6}$ & 200 & 6 & 0.249 & 0.270 & 8.19 \\
\hline $\operatorname{Imp}_{7}$ & 150 & 8 & 0.250 & 0.267 & 6.97 \\
\hline $\operatorname{Imp}_{8}$ & 125 & 9.6 & 0.250 & 0.266 & 6.25 \\
\hline $\operatorname{Imp}_{9}$ & 100 & 12 & 0.248 & 0.263 & 6.03 \\
\hline $\operatorname{Imp}_{10}$ & 80 & 15 & 0.246 & 0.260 & 5.59 \\
\hline $\operatorname{Imp}_{11}$ & 60 & 20 & 0.242 & 0.255 & 5.23 \\
\hline $\operatorname{Imp}_{12}$ & 50 & 24 & 0.239 & 0.251 & 5.09 \\
\hline $\operatorname{Imp}_{13}$ & 40 & 30 & 0.233 & 0.246 & 5.17 \\
\hline $\operatorname{Imp}_{14}$ & 30 & 40 & 0.226 & 0.237 & 5.26 \\
\hline $\operatorname{Imp}_{15}$ & 20 & 60 & 0.208 & 0.223 & 7.65 \\
\hline
\end{tabular}
the derived equation on the range of the parameters studied.

Table 5: Proposed equation and FE ultimate strength comparison.

\subsection{Proposed Tolerance Limit Equation}

\subsubsection{Tolerance Comparison}

Specific codes give tolerance limits on imperfections in the web of plate girders. Past studies $[5,6,8]$ have shown that these limits are usually too strict and conservative. Also, these limits are found not to be completely inclusive [7]. Thus, a normalised drop in strength derived a less conservative and more inclusive parameter-wise equation for tolerance limit. 


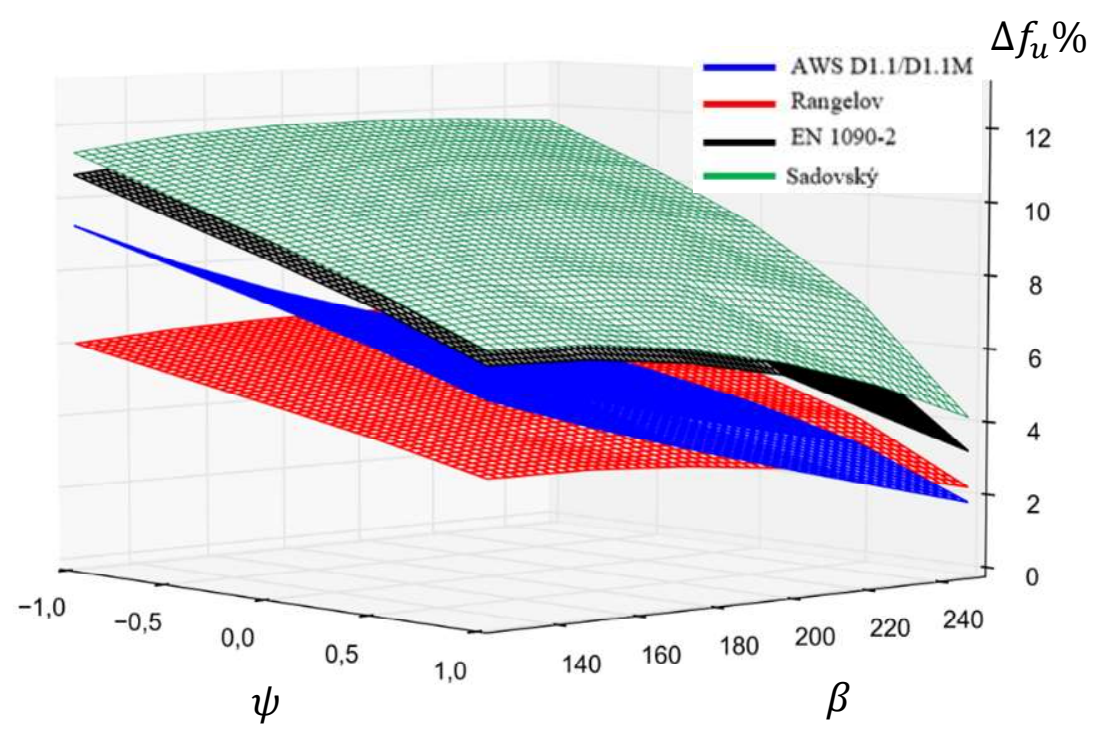

Figure 11: 3D graphical representation of the drop in strength at given tolerance limits.

To achieve this, the drop in ultimate strength of webs from the assumed perfect web with minimum imperfection amplitude, $\delta=\operatorname{Imp}_{1}$ were calculated using the derived ultimate strength equation. The results are shown in Figure 11.

It was then realised that the tolerance limit given by AWS D1.1/D1.1M [39] and that given by Rangelov [5] are too conservative. Also, it was realised that the EN 1090-2 tolerance limit [40], with a maximum drop of 11.15\%, has an appropriate drop and is a conservative form of the limit given by Sadovský [6].

The maximum drop in the strength of $11.15 \%$ was then fixed as a normalised drop for the range of values of the study. Thus, the imperfection amplitude that corresponds to this normalised fixed drop was determined using the derived strength equation. This imperfection amplitude was represented on the graph of Figure 12. Also, the tolerances given by AWS D1.1/D1.1M and EN 1090-2 were plotted for comparison.

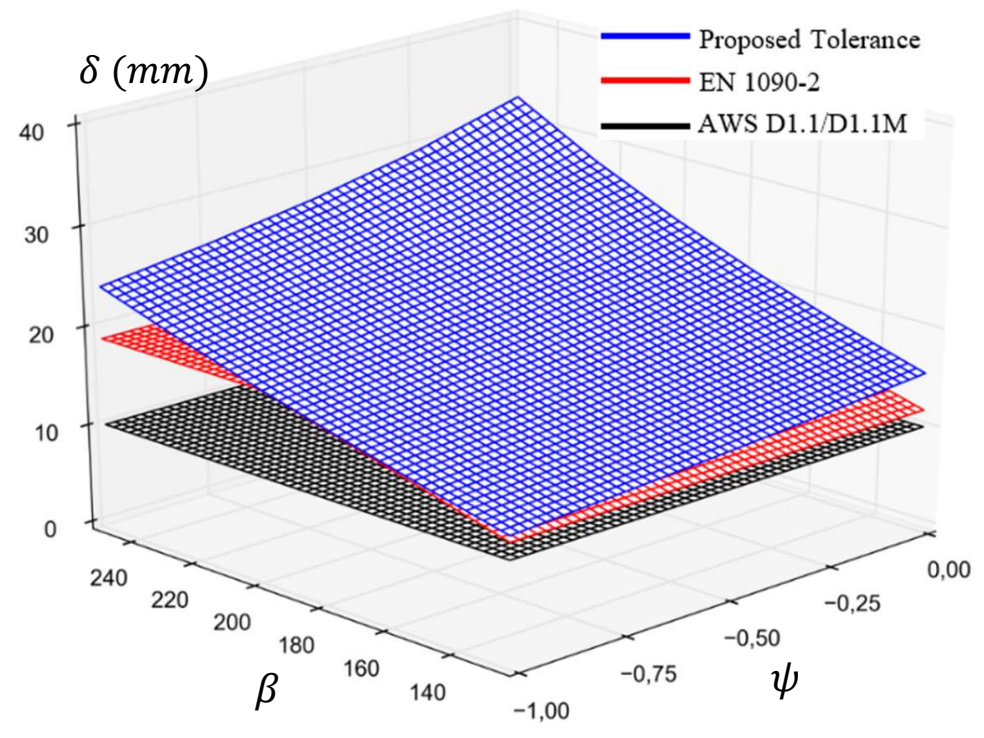

Figure 12: Comparison between the proposed tolerance limit and codes specification limits.

The results obtained show that the initial imperfection amplitude at a fixed global drop in the strength of 11.15\% was always higher than AWS D1.1/D1.1M and EN 1090-2 tolerance limits with AWS D1.1/D1.1M tolerance found to be too conservative. Also, for the normalised drop in strength, EN 1090-2 tolerance limit was found to be 
slightly conservative at low slenderness ratio values during pure bending. The conservative nature is seen on the graph as both the proposed tolerance and EN 1090-2 limits are tangent to each other. As the slenderness ratio becomes more than 200 and the stress ratio increases, the limit given by EN 1090-2 becomes more and more conservative. Therefore, for a normalised drop in strength, the tolerance limits proposed by both codes can be relaxed.

\subsubsection{Derivation}

From the graph of Figure 12, a simplified equation can be derived which explicitly describes the proposed tolerance limit as a function of stress ratio and slenderness ratio. Equation (3.3) was derived by using a multiple nonlinear regression analysis technique employed in Curve Expert Professional [38]. The equation obtained is such that the correlation coefficients of determination are $\mathrm{R}^{2}=98.41 \%$ and $\mathrm{R}=99.20 \%$. These results showed good conformity between the derived equation and the proposed tolerance curve of Figure 12.

$$
\begin{gathered}
\qquad \psi \in[-1,0] \text { and } \forall \beta \in[125,250] \\
\text { Proposed Tolerance Limit }=\frac{(80 \cdot \psi+185)^{2}+(\beta+75)^{2}}{4500}
\end{gathered}
$$

\subsubsection{Verification}

To verify the equation derived, a web model, different from the ones used in the analyses, was selected from the range of study. This web had properties given in equation (3.2).

The chosen web of plate girder is subjected to an eccentric compression with stress ratio $\psi=-0.5$. It is modeled using the verified FE modeling procedure with an imperfection amplitude equal to $21.48 \mathrm{~mm}$ (obtained from the derived tolerance limit equation). The FE results obtained $\left(146.51 \mathrm{~N} / \mathrm{mm}^{2}\right)$ with this imperfection is compared to the results obtained $\left(157.97 \mathrm{~N} / \mathrm{mm}^{2}\right)$ from the supposed perfect structure $\left(\operatorname{Imp}_{1}=0.012 \mathrm{~mm}\right)$. The drop in strength at the given tolerance limit is found to be $7.25 \%$. This percentage is in perfect agreement with the normalised maximum drop of $11.15 \%$. Thus, this confirms the reliability of the derived equation in the range of the parameters studied.

Thus, for the web understudy of depth $1500 \mathrm{~mm}$, the derived and proposed tolerance limit equation provides an EN 1090-2 tolerance relaxation of up to $40 \%$ in less slender webs and $60 \%$ in more slender webs. When compared to AWS D1.1/D1.1M, there is a possible relaxation of around $80 \%$ in less slender webs and close to $200 \%$ in more slender webs.

These relaxation percentages strongly depend on the loading condition (stress ratio), as the stated percentages tend to reduce when the loading tends to be more of pure bending (experienced in bisymmetric plate girders). Therefore, the codes' tolerance limit on monosymmetric plate girders (eccentric loading) with thin webs (high slenderness ratio) is strict and should be relaxed. Also, in contrast to the tolerance limit given by EN 1090-2 and AWS D1.1/D1.1M, the proposed tolerance limit with a normalised drop of $11.15 \%$ is a function of both the loading condition (stress ratio) and the slenderness ratio.

\section{Conclusion}

In order to investigate the effects of web aspect ratio, slenderness ratio, stress ratio, and initial imperfection amplitude on the ultimate strength of I-shaped steel plate girders subjected to local web-bend buckling and their effect on web imperfection tolerance limit, a parametric study was performed. 36 perfect and 612 imperfect web models were modeled and analysed using Abaqus/CAE FE linear buckling and GMNIA analyses. Prior to the parametric study, preliminary studies were done to verify the FE modeling procedures adopted based on Basler's experimental findings [36]. After investigating the FE GMNIA results, it was found that the analytical ultimate strength results provided by the European code were found to be overestimated by $24.91 \%$ with respect to the FE results; this is backed by Fukumoto's findings [11, 12]. This overestimation could lead to a sudden failure of a plate girder during its launching phase. The length of the web does not affect its ultimate strength, provided it is 
maintained within the limits of this study (aspect ratio ranging from 1 to 2). A decrease in the web's thickness (increase in slenderness ratio) reduces the web's ultimate strength.

Furthermore, a move from the use of bisymmetric to the use of monosymmetric plate girders (increase in stress ratio) implies a reduction in the ultimate strength. Also, a regression analysis was done to propose an ultimate strength equation and a tolerance limit equation based on the fact that strength reduction is equal to the maximum reduction provided by the American and European codes (11.15\%). It was then noticed that for monosymmetric plate girders, the European tolerance limit could be relaxed by $40 \%$ in less slender webs and $60 \%$ in more slender webs compared to the American limit, which can be relaxed to around $80 \%$ in less slender webs and close to $200 \%$ in more slender webs. The relaxed tolerance limit equation will be highly welcomed by fabricators as it will help to reduce costly web straightening operations. To erectors, the equations will serve as an on-site tool to easily compute the ultimate strength and imperfection limit of a web of a plate girder. As perspectives, further numerical studies should be performed to study the influence of both patch and shear loadings on the proposed equations. Experimental studies are also recommended to confirm, under a more global behavior, the proposed equations.

\section{References}

[1] Ghadami A, Broujerdian V. Shear behavior of steel plate girders considering variations in geometrical properties. J. Constr. Steel Res. 2019; 153: pp. 567-577, doi: 10.1016/j.jcsr.2018.11.009.

[2] Tetougueni C. D., Maiorana E., Zampieri P., Pellegrino C. Plate girders behaviour under in-plane loading: A review. Eng. Fail. Anal. 2019; 95(8): pp. 332-358, doi: 10.1016/j.engfailanal.2018.09.021.

[3] McAnallen LE, Padilla-Llano DA, Zhao X, Moen CD, Schafer BW, Eatherton MR. Initial geometric imperfection measurement and characterization of cold-formed steel C-section structural members with 3D non-contact measurement techniques. Struct. Stab. Res. Counc. Annu. Stab. Conf. 2014, SSRC 2014, pp. 566-590, 2014.

[4] Massonet C. Tolerances in steel plated structures. IABSE Surv., 1980.

[5] Rangelov N. A theoretical approach to the limiting of initial imperfections in steel plates. Der Stahlbau, 1992; 61(5): pp. 151-156.

[6] Sadovský Z, Baláž I. Tolerances of initial deflections of steel plates and strength of I cross-section in compression and bending. J. Constr. Steel Res. 1996; 38(3): pp. 219-238, doi: 10.1016/0143-974X(96)00020-X.

[7] Maiorana E, Pellegrino C, Modena C. Imperfections in steel girder webs with and without perforations under patch loading. J. Constr. Steel Res. 2009; 65(5): pp. 1121-1129, doi: 10.1016/j.jcsr.2008.10.007.

[8] Kala J, Škaloud M, Melcher J, Kala Z. Imperfections in steel plated structures and their impact on ultimate strength. Proc. SDSS' Rio 2010 Int. Colloq. Stab. Ductility Steel Struct. 2010; 2: pp. 779-785.

[9] Beg D, Kuhlmann U, Davaine L, Braun B. Design of Plated Structures_Eurocode 3_ Design of Steel Structures, Part 1-5 - Design of Plated Structures, First Edition. 2011.

[10] EN 1993-1-5:2006 (E) Design of steel structures - Part 1-5: Plated structural elements. 2011; 1: no. 2005.

[11] Clarin M. Plate Buckling Resistance - Patch Loading of Longitudinally Stiffened Webs and Local Buckling. 2007.

[12] Fukumoto Y, Itoh Y. Basic From Strength Test of Steel Plates. 1984; 1: no. 344.

[13] Timoshenko SP, Gere JM, Prager W. Theory of Elastic Stability, Second Edition. Journal of Applied Mechanics, 1962; 29(1): pp. 220-221, doi: 10.1115/1.3636481.

[14] Ziemian RD, Wiley J. Guide To Stability Design Criteria for Metal Structures. 2010.

[15] Salman JC, Johnson EJ. Steel structures design \& behaviour. 1996.

[16] Segui WT. Steel Design, 2013; 53:no. 9.

[17] Alinia MM, Gheitasi A, Shakiba M. Postbuckling and ultimate state of stresses in steel plate girders. Thin-Walled Struct., 2011; 49(4): pp. 455-464, doi: 10.1016/j.tws.2010.12.008.

[18] Graciano C, Casanova E, Martínez J. Imperfection sensitivity of plate girder webs subjected to patch loading. J. Constr. Steel Res. 2011; 67(7): pp. 1128-1133, doi: 10.1016/j.jcsr.2011.02.006.

[19] Shin DK, Cho EY, Kim K. Ultimate flexural strengths of plate girders subjected to web local buckling. Int. J. Steel Struct. 2013; 13(2): pp. 291-303, doi: 10.1007/s13296-013-2008-3.

[20] Kassem MR. The Behaviour and Design of Transverse Web Stiffeners in Bridge Girders. 1989.

[21] Loorits K, Mekaniikka R. Classification of Cross Sections for steel beams in Different Design Codes. Raken. Mek. 1995; 28(1): pp. $19-33$.

[22] ABAQUS. Abaqus 6.14. Abaqus 6.14 Anal. User's Guid., 2014; p. 14.

[23] Helwig T, Reagan H, Zhang Y, Espinoza O, Mercan B. Fabricated Plate Tolerances for Steel Bridges. 2015.

[24] Hayward BA, Sadler N, Tordoff D. A Practical Approach to Design for Efficient Fabrication and Construction, $2002 ;$ no. 34. 
[25] Jayanta S. Local buckling and section classification. 2016; pp. 1-8, [Online]. Available: http://www.steelinsdag.org/TeachingMaterial/Chapter8.pdf.

[26] AutoDesk Inc. How to Perform a Mesh Convergence Study | Simulation Mechanical | Autodesk Knowledge Network. 2017; [Online]. Available: $\quad$ https://knowledge.autodesk.com/support/simulation-mechanical/learn-explore/caas/sfdcarticles/sfdcarticles/How-toPerform-a-Mesh-Convergence-Study.html.

[27] Pham NH, Pham CH, Rasmussen KJR. Incorporation of measured geometric imperfections into finite element models for cold-rolled aluminium sections. Lect. Notes Civ. Eng. 2018; 8: pp. 161-171, doi: 10.1007/978-981-10-6713-6_15.

[28] Ellobody E. Finite Element Analysis and Design of Steel and Steel-Concrete Composite Bridges, 1st ed. Butterworth-Heinemann, 2014.

[29] Galishnikova V, Dunaiski P, Pahl PJ. Geometrically Non-linear Analysis of Plane Trusses and Frames. 2009.

[30] McGuire W, Gallagher RH, Ziemian RD. Matrix Structural Analysis, With MASTAN2. 1999; p. 480, [Online]. Available: http://books.google.com/books/about/Matrix_Structural_Analysis_With_MASTAN2.html?id=_I4AAAAACAAJ\&pgis=1.

[31] Przemieniecki JS. Theory of Matrix Structural Analysis. 1968.

[32] Ritter K. Nonlinear problems. 2000; pp. 213-225, doi: 10.1007/bfb0103942.

[33] Vasios N. Nonlinear Analysis of Structures. NASA Contract. Reports, 2015.

[34] Wood RD. Analysis of geometrically nonlinear structures, 1997; 28: no. 1.

[35] Basler K, Bung-Tseng Y, Mueller JA, Thürlimann B. Web buckling tests on welded plate girders - Overall introduction and Part 1 The test girders. Fritz Eng. Lab. Lehigh Univ. 1960; 165: 251-11.

[36] Basler K, Yen BT, Mueller JA, Thurlimann B. Web buckling tests on welded plate girders. 1960.

[37] Hyams DG. GraphExpert professional documentation. Release 1.1.3. 2014

[38] Hyams DG. CurveExpert Professional Documentation. Hyams Dev. 2018; p. 213, [Online]. Available: https://bit.ly/2UBpckG.

[39] AWS D1.1/D1.1M:2010 American Welding Society, Structural Welding Code - Steel. 2010.

[40] EN 1090-2:2018 (E) Execution of steel structures and aluminium structures - Part 2: Technical requirements for steel structures. 2018. 